\title{
A Retrospective Analysis of Deep Surgical Site Infection Treatment after Instrumented Spinal Fusion with the Use of Supplementary Local Antibiotic Carriers
}

\author{
Daniël M.C. Janssen ${ }^{\bowtie}$, Maud Kramer, Jan Geurts, Lodewijk v Rhijn, Geert H.I.M. Walenkamp, Paul C. \\ Willems \\ Department of Orthopaedic Surgery, Research School CAPHRI, Maastricht University Medical Center, Maastricht, the Netherlands \\ $\bowtie$ Corresponding author: dmc.janssen@alumni.maastrichtuniversity.nl \\ (c) Ivyspring International Publisher. This is an open access article distributed under the terms of the Creative Commons Attribution (CC BY-NC) license \\ (https://creativecommons.org/licenses/by-nc/4.0/). See http://ivyspring.com/terms for full terms and conditions.
}

Received: 2017.11.13; Accepted: 2018.04.13; Published: 2018.05.21

\begin{abstract}
Background: There is no generally established treatment algorithm for the management of surgical site infection (SSI) and non-union after instrumented spinal surgery. In contrast to infected hip- and knee- arthroplasties, the use of a local gentamicin impregnated carrier in spinal surgery has not been widely reported in literature.

Patients and methods: We studied 48 deep SSI and non-union patients after instrumented spine surgery, treated between 1999 and 2016. The minimum follow-up was 1.5 years. All infections were treated with a treatment-regimen consisting of systemic antibiotics and repetitive surgical debridement, supplemented with local gentamicin releasing carriers.

We analysed the outcome of this treatment regimen with regard to healing of the infection, as well as patient- and surgery-characteristics of failed and successfully treated patients.

Results: 42 of the $48(87.5 \%)$ patients showed successful resolution of the SSI without recurrence with a stable spine at the end of treatment.

36 patients' SSI were treated with debridement, local antibiotics, and retention or eventual restabilization of the instrumentation in case of loosening. 3 patients were treated without local antibiotics because of very mild infection signs during the revision operation. 3 patients were treated with debridement, local antibiotics and removal of instrumentation. One of these patients was restabilized in a second procedure.

Infection persisted or recurred in 6 patients. These patients had a worse physical status with a higher ASA-score. Staphylococcus aureus was the most frequent causative microorganism.

Interpretation: Debridement and retention of the instrumentation, in combination with systemic antibiotics and the addition of local antibiotics provided a successful treatment for SSI and non-union after instrumented spinal fusion.
\end{abstract}

\section{Introduction}

The incidence of surgical site infection (SSI) after spinal surgery ranges from 2 to $12 \%$, depending on diagnosis, surgical approach, use of spinal instrumentation, and the complexity of the procedure [1-4].

SSI is a devastating complication that leads to prolonged treatment, with the need for subsequent reoperations and substantially increased overall health care costs. Moreover, SSI after instrumented spinal surgery is associated with higher rates of morbidity and mortality, and has a negative impact on functional clinical outcome [5-7].

There is no generally established treatment protocol for the management of deep SSI after 
instrumented spinal surgery. As we know from SSI after general fracture management with osteosynthesis, instrumentation is preferably left in situ as preservation of stability is crucial to allow for bony union while the infection is managed. Likewise, in spinal fusion, as long as bony union has not occurred, stable instrumentation material should be left in situ in order to prevent loss of correction or development of pseudarthrosis due to mechanical instability [8,9]. After bony consolidation, the instrumentation can be removed if necessary in a second stage for complete cure of the infection [10].

\section{Gentamicin impregnated carriers}

Polymethylmethacrylate (PMMA) or bone cement is able to release admixed powdery substances if these are soluble in water and heat stable during polymerization [11]. Buchholz admixed four heat stable antibiotic powders with bone cement and found that, except for tetracycline, the antibiotics indeed were released by a diffusion process for at least 2 weeks in a bactericidal concentration[11]. Subsequently, many handmade and commercially made combinations of antibiotics and bone cements were tested, of which gentamicin in combination with Palacos bone cement provided the best antibiotic release after implantation and best stability during polymerization.[12-14]

Gentamicin is very suitable for prevention or treatment of orthopedic infections since it exhibits a broad antibacterial spectrum including gram-positive and gram-negative germs, and a good bactericidal effect in low concentrations with a low rate of resistances development [15].

Gentamicin-impregnated bone cement was first introduced to prevent SSI after cemented implantation of joint arthroplasties[16]. Once on the market, it was also used to treat osteomyelitis by filling bone cavities after debridement. Because small beads of bone cement mixed with antibiotics were proven to be more effective, non-absorbable gentamicin impregnated PMMA beads (Septopal®) were commercially produced for local antibiotic treatment of infections, by admixing gentamicin to the liquid monomer and polymer powder, in combination with glycine as a filler to promote the gentamicin release [17].

In view of the successful treatment with these non-absorbable drug carriers, endeavours were made to develop absorbable materials that no longer needed removal. [18] Because collagen carriers are fully absorbed, gentamicin-collagen products can be used in one-step surgical procedures.

Pharmacokinetic release models have shown that the release of gentamicin from collagen fleeces is more rapid and less longstanding as compared to
PMMA-beads [19]. Both carriers have shown a high local gentamicin concentration without toxic concentrations in the blood $[19,20]$.

Although commonly used in prosthetic joint infections (PJI) and osteomyelitis [21-23], the use of antibiotic loaded carriers in SSI after instrumented spinal fusion has not been widely reported [8, 20-24]. Because of good results in the use of gentamicin PMMA-beads or fleeces in the treatment of prosthetic joint infections [22, 23] we incorporated local gentamicin in the treatment of SSI after instrumented spinal fusion.

The aim of this study was to assess the treatment results after the use of a local gentamicin impregnated carriers, supplementary to operative debridement and administration of systemic antibiotics for SSI without union after instrumented spinal fusion, with an in-depth analysis of failed cases.

\section{Material and methods}

This is a retrospective case-series analysis of all non-union, deep SSI patients after instrumented thoracolumbar spinal fusion procedures that had been performed in the Department of Orthopedics of the Maastricht University Medical Centre, a secondary and tertiary academic referral center for spinal pathology and for orthopaedic infections, from January 1999 up to December 2015.

\section{Diagnosis}

The diagnosis of surgical site infection was based on criteria as described by the CDC (Centre for Disease Control and prevention) [25] and the Dutch national PREZIES network (prevention of hospital infections through surveillance) [26]. According to these criteria, a SSI was considered to be deep if it presented at the site of the operation with involvement of subfascial tissue [25].

\section{Patients}

We diagnosed $62 \quad(6,9 \%)$ deep surgical site infections (30 female, 32 male) out of 898 instrumented spinal surgery procedures (14 anterior approach, 884 posterior approach). 14 patients (4 female, 10 male) with an SSI were excluded from analysis: One patient had been treated for spondylodiscitis as the index operation, two patients did not receive treatment for SSI because of terminal illness and one patient was excluded because of loss to follow up. 10 patients had a late SSI with bony union of the spondylodesis. These 10 union SSI were all successfully treated with removal of the instrumentation and with additional local antibiotic administration in 2 patients. We included 48 patients (47 after posterior instrumented spinal fusion and 1 
after anterior instrumented spinal fusion).

\section{Treatment protocol}

Deep infections of instrumented spinal fusion without bony consolidation, and without signs of implant loosening were treated by surgical debridement, systemic antibiotics, irrigation and implant retention (DAIR), in combination with application of antibiotics loaded carriers (gentamicin PMMA-beads or fleeces).

In case of instrumentation loosening and an unstable spine, new instrumentation was inserted for re-stabilisation. (Figure 1)

The procedure consisted of debridement with removal of loose bone graft material, pulsed lavage with at least 3 litres of Ringer lactate and either retention, removal or re-stabilisation of the instrumentation depending on the stability of the instrumentation and spine. The patients were treated with systemic and local antibiotic therapy. As local antibiotic carrier we preferably used gentamicin PMMA beads with a diameter of $7 \mathrm{~mm}$, containing 7.5 $\mathrm{mg}$ gentamicin sulphate, in chains of 30 or 60 beads (Septopal ${ }^{\circledR}$, Merck GmbH, Darmstadt, Germany;

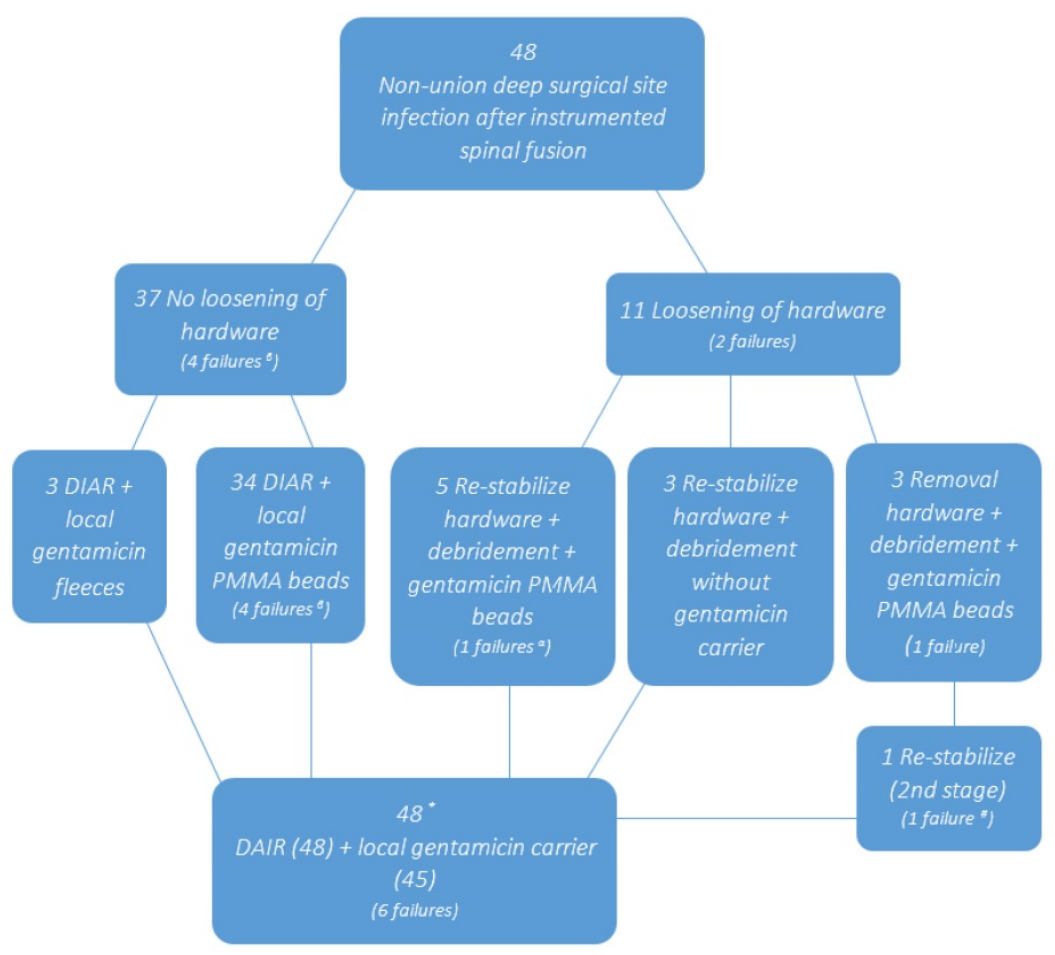

Figure 1. Treatment algorithm of deep surgical site infection after instrumented spinal fusion. $* 45 / 48$ infections were treated with debridement of the wound and a local gentamicin carrier (gentamicin fleeces in $3 \mathrm{SSI}$ and gentamicin PMMA beads in $42 \mathrm{SSI}$ ) and 3/48 were treated without local gentamicin treatment because of very mild signs of a deep infection during operation. ${ }^{\beta} 3 / 4$ failures died sepsis-related during infection treatment. One failure presented with a recurrent infection with the same initial micro-organism (Staphylococcus aureus) that was successfully treated with removal of the instrumentation and local gentamicin PMMA beads. ${ }^{\alpha} 1$ failure died during infection treatment because of sepsis. \# 1 failure was a recurrence of infection of the anterior instrumentation that occurred more than 3 years after the secondary restabilization. This patient died during the second infection treatment because of a poor health condition (terminal metastatic renal cancer)
Biomet $\mathrm{GmbH}$, Berlin, Germany). We packed as many beads in the infected tissues as tensionless wound closure would allow in order to create a high local gentamicin concentration. Wounds were fully closed and the gentamycin beads were removed in a second procedure 2 weeks later.

Multiple tissue samples were taken for bacteriological cultures right before the administration of systemic antibiotics. The samples were cultured in the microbiology laboratory for at least 2 weeks in order to also detect slow growing microorganisms. The minimal inhibitory concentration (MIC) value for gentamicin of the specific bacteria strain was then determined.

If infection signs had not resolved, the gentamicin beads were removed, a new debridement was performed, and new beads were left behind during a second procedure 2 weeks later.

In case of very mild intraoperative infection signs, one debridement was considered to be enough and only gentamicin collagen fleeces were used as local gentamicin impregnated antibiotic carrier. Gentamicin collagen fleeces (Septocoll ${ }^{\circledR}$, containing $116 \mathrm{mg}$ gentamicin sulphate and $350 \mathrm{mg}$ gentamicin crobephate in $320 \mathrm{mg}$ equine collagen fleece with a size of $10 \times 8 \mathrm{~cm}$; Merck $\mathrm{GmbH}$, Darmstadt, Germany; Biomet $\mathrm{GmbH}$, Berlin, Germany) were applied before closing the wound, to prolong the period with local antibiotics and obviate the need for removal of the beads in another operation.

Spinal instrumentation was removed if, infection persisted according to clinical and laboratory parameters despite one or more treatment periods of 2 weeks with gentamicin beads. In case of instability because of non-union as determined intraoperatively by visible motion across the fused segment(s) and the absence of bony continuity on inspection, the spine was restabilized directly with renewed instrumentation [27, 28]. The infection treatment was then continued with the local application of gentamicin PMMA beads and intravenous administration of antibiotics.

\section{Systemic antibiotics}

The surgical treatment was combined with high dosed systemic antibiotics, usually for a period of approximately 3 months, including a minimum of two weeks intravenous 
administration during hospitalization and continued oral administration after discharge from the hospital. The choice and exact duration of the systemic antibiotic treatment was decided on an individual basis and based on antibiotic resistance pattern of the causative bacteria by consultation of a microbiologist specialized in orthopaedic infections.

Erythrocyte sedimentation rate (ESR), C-reactive protein (CRP) and white blood cell counts (WBC) were measured twice a week during hospitalisation and at all outpatient control visits for monitoring of infection healing. We considered these parameters as normal when CRP and WBC counts were within the normal range $(C R P<10 \mathrm{mg} / \mathrm{L} ; \quad W B C<10,000$ cells/mcL) at 2 subsequent outpatient control visits, and the ESR was decreased to less than $30 \mathrm{~mm} / \mathrm{h}$ in patients without systemic disease and cessation of systemic antibiotic treatment.

\section{Outcome}

The treatment was considered successful when at follow up the infection was eradicated (normalized inflammatory blood markers and no clinical signs of infection) with a stable spine by instrumentation or by osseous fusion. Failure was diagnosed if the infection was not eradicated.

The subjective outcome (disabling back pain or leg pain with limitations in activities of daily living (ADL)) were noted as "yes" or "no" at the end of the follow-up at the outpatient clinic.

The follow-up period started at the date of the first operation for infection, and ended on the date of the last outpatient clinic visit, the last contact with the family doctor or the date of death. The minimum follow up was 1.5 year or shorter in case of death, either related or not to the SSI.

\section{Statistical analysis}

Patient characteristics (gender, age, BMI, smoking status, comorbidities, ASA-score, medication, trauma, radiation therapy, blood values, revision surgery, interval between primary surgery and infection treatment, antibiotic use and MIC genta) and operation variables (primary indication, combination surgery with a second incision, fused levels, anatomical levels, graft use, cage use, dural tear, micro-organism and soft tissue condition) were presented as either median with total range, or as mean with standard deviation (SD).

Additionally, the odds ratios (OR) with 95\% confidence intervals (CI) were calculated for all patients' characteristics and risk factors for poor treatment outcome. The Mann Whitney U test was used to analyse differences of continuous variables between successfully treated patients and failures.
SPSS (version 17.0) was used for all statistical calculations.

\section{Results}

48 patients with a deep SSI without bony union were treated, of which $42(87.5 \%)$ were treated successfully. Recurrence of infection occurred after more than 2 years in 2 patients. Four patients died during infection treatment because of sepsis (Table 1 and Figure 2).

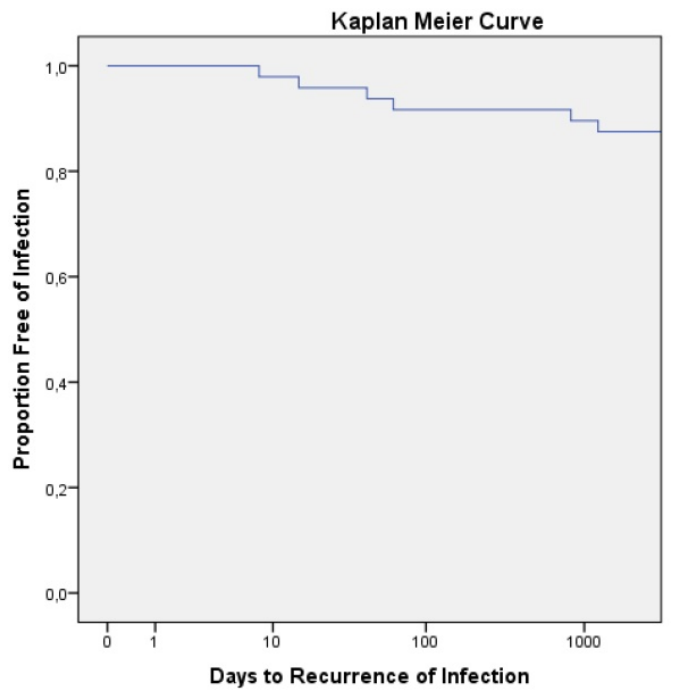

Figure 2. Kaplan-Meier survival curve that represents the proportion of all patients free of infection after treatment for deep SSI after instrumented spinal fusion.

37 of 48 patients were treated with debridement, retention of the stable instrumentation (DAIR), and local antibiotics: 33 of these 37 were treated successfully, while 4 failed.

8 of the 48 patients were treated with DAIR after restabilization of loose instrumentation of which 3 without local antibiotics, because there were minimal signs of infection intraoperatively.

Instrumentation was removed without spinal restabilization in 3 of the 48 patients, as the lumbar spine was considered stable after instrumentation removal. These 3 cases were all treated with gentamicin PMMA beads. One of these patients required anterior restabilization in a second stage after 2 periods of treatment with gentamicin PMMA beads. (Figure 1 )

6 of the 48 patients were treated with only one debridement, and 24 were treated with 2 debridements, whereas 15 needed 3 debridements and only 3 patients needed 4 debridements of the wound.

The median time of systemic intravenous antibiotic treatment was 41 (3-95) days, followed by oral treatment for another 43 (0-196) days. The median total antibiotic therapy time was 84 (6-251) days. Oral 
antibiotic treatment at the outpatient clinic was stopped when clinical and laboratory parameters were considered as normal. Staphylococcus aureus was found as the most frequent $(24 / 48)$ causative microorganism (Table 2). There was no significant difference with respect to causative micro-organism between the failed and the successfully treated patients. No relation could be found between the MIC value for gentamicin of the causative bacteria and the success rate of the infection treatment. (Table 3 )

5 of the 6 patients $(83 \%)$ in whom the infection treatment failed had an ASA-score $>2$ compared to only 12 of $42(29 \%)$ in the population with a successful treatment.

There were no other isolated patient characteristics or operation-related variables that differed significantly between the 6 patients in whom the infection treatment failed and the 42 successfully treated patients. (Table 2 and 3 )

At the end of follow-up, 5 patients (10.4\%) complained of residual disabling back pain with limitations in ADL, 2 patients (4.2\%) complained of persisting disabling leg pain with limitations in ADL, and 3 patients $(6.3 \%)$ had residual disabling back and leg pain with limitations in ADL.

In summary, $87.5 \%(42 / 48)$ of all patients with a SSI and non-union after an instrumented spinal procedure where treated successfully with a treatment regimen consisting of systemic antibiotics and repetitive surgical debridement supplemented with local gentamicin releasing carriers. 8\% (4/48) died during infection treatment because of sepsis and in $4 \%(2 / 48)$ recurrence of infection occurred after more than 2 years.

Table 1. Details of the patients

\begin{tabular}{|c|c|c|c|c|c|c|c|}
\hline Diagnosis & pathogen & $\begin{array}{l}\text { Interval } \\
\text { (days) }\end{array}$ & $\begin{array}{l}\text { Debride- } \\
\text { ments }\end{array}$ & FU & Outcome & Treatment & Subjective outcome \\
\hline Fracture with threatened myelum & S. viridans & 1 & 1 & 1062 & Success & $\begin{array}{l}\text { Debridement, restabilization, no } \\
\text { local } \mathrm{AB}\end{array}$ & Back pain \& disabilities in ADLs \\
\hline Scoliosis (degenerative) & E. Coli & 8 & 2 & 962 & Success & DIAR + fleeces & Back pain, no disabilities in ADLs \\
\hline Degenerative spondylolysis & E. coli & 9 & 3 & 1159 & Success & DIAR + beads & Back pain, no disabilities in ADLs \\
\hline Failed previous spine surgery & S. Aureus & 9 & 3 & 1195 & Success & DIAR + beads & No pain or disabilities in ADLs \\
\hline HNP with threatened myelum & S. Aureus & 9 & 3 & 882 & Success & DIAR + beads & Disabilities in ADLs without pain \\
\hline RIP with threatened myelum & E. Coli & 10 & 2 & 875 & Success & $\begin{array}{l}\text { Debribement, restabilization + } \\
\text { beads }\end{array}$ & Leg pain \& disabilities in ADLs \\
\hline RIP with threatened myelum & mixed flora & 10 & 2 & 1277 & Failure & $\begin{array}{l}\text { Removal implants }+ \text { beads, } \\
\text { restabilization in second } \\
\text { procedure }\end{array}$ & No pain or disabilities in ADLs \\
\hline Failed previous spine surgery & mixed flora & 11 & 1 & 371 & Success & DIAR, no local AB & No pain or disabilities in ADLs \\
\hline Fracture with threatened myelum & E. cloacae & 12 & 2 & 1185 & Success & DIAR + beads & No pain or disabilities in ADLs \\
\hline Degenerative spondylolisthesis & mixed flora & 12 & 3 & 1402 & Success & DIAR + beads & No pain or disabilities in ADLs \\
\hline $\begin{array}{l}\text { Fracture without threatened } \\
\text { myelum }\end{array}$ & S. Aureus & 12 & 2 & 733 & Success & $\begin{array}{l}\text { Debribement, restabilization + } \\
\text { beads }\end{array}$ & Back pain, no disabilities in ADLs \\
\hline Spinal stenosis & S. Aureus & 13 & 3 & 406 & Success & DIAR + beads & No pain or disabilities in ADLs \\
\hline $\begin{array}{l}\text { Fracture without threatened } \\
\text { myelum }\end{array}$ & E. coli & 13 & 2 & 884 & Success & DIAR + beads & Disabilities in ADLs without pain \\
\hline $\begin{array}{l}\text { Fracture without threatened } \\
\text { myelum }\end{array}$ & S. Aureus & 13 & 2 & 1092 & Failure & DIAR + beads & Back pain, no disabilities in ADLs \\
\hline Degenerative spondylolisthesis & E. Coli & 13 & 1 & 1106 & Success & DIAR + fleeces & No pain or disabilities in ADLs \\
\hline Degenerative spondylolisthesis & E. cloacae & 14 & 2 & 519 & Success & DIAR + beads & $\begin{array}{l}\text { Back \& leg pain \& disabilities in } \\
\text { ADLs }\end{array}$ \\
\hline Degenerative spondylolisthesis & S. Aureus & 14 & 4 & 1163 & Success & DIAR + beads & $\begin{array}{l}\text { Back \& leg pain, no disabilities in } \\
\text { ADLs }\end{array}$ \\
\hline Degenerative spondylolisthesis & S. Aureus & 15 & 3 & 251 & Success & DIAR + beads & No pain or disabilities in ADLs \\
\hline Degenerative spondylolisthesis & S. Aureus & 15 & 3 & 1007 & Success & DIAR + beads & No pain or disabilities in ADLs \\
\hline Degenerative spondylolisthesis & S. pyogenes & 15 & 1 & 1334 & Success & DIAR + beads & Back pain \& disabilities in ADLs \\
\hline Spinal stenosis & S. Aureus & 15 & 2 & 1483 & Success & DIAR + beads & Back pain \& disabilities in ADLs \\
\hline Lytic spondylolisthesis & mixed flora & 16 & 2 & 1037 & Success & DIAR + beads & No pain or disabilities in ADLs \\
\hline Degenerative spondylolisthesis & S. Aureus & 16 & 3 & 1039 & Success & DIAR + beads & Back pain, no disabilities in ADLs \\
\hline Pseudoartrosis & S. Aureus & 16 & 1 & 1219 & Success & Removal implants + beads & No pain or disabilities in ADLs \\
\hline Degenerative spondylolisthesis & S. mitis & 17 & 3 & 762 & Success & DIAR + beads & No pain or disabilities in ADLs \\
\hline Scoliosis (degenerative) & CNS & 17 & 2 & 854 & Success & DIAR + beads & Leg pain \& disabilities in ADLs \\
\hline Degenerative spondylolisthesis & S. Aureus & 17 & 3 & 745 & Success & Removal implants + beads & $\begin{array}{l}\text { Back \& leg pain \& disabilities in } \\
\text { ADLs }\end{array}$ \\
\hline Degenerative spondylolisthesis & S. Aureus & 18 & 1 & 8 & Failure & DIAR + beads & Dead \\
\hline Degenerative spondylolisthesis & mixed flora & 18 & 2 & 1466 & Success & DIAR + beads & No pain or disabilities in ADLs \\
\hline Degenerative spondylolisthesis & CNS & 19 & 3 & 976 & Success & DIAR + beads & No pain or disabilities in ADLs \\
\hline $\begin{array}{l}\text { Fracture without threatened } \\
\text { myelum }\end{array}$ & S. Aureus & 20 & 1 & 15 & Failure & DIAR + beads & Dead \\
\hline Fracture with threatened myelum & E. coli & 20 & 2 & 275 & Success & DIAR + beads & Disabilities in ADLs without pain \\
\hline Degenerative spondylolisthesis & mixed flora & 20 & 4 & 741 & Success & $\begin{array}{l}\text { Debribement, restabilization + } \\
\text { beads }\end{array}$ & $\begin{array}{l}\text { Back \& leg pain \& disabilities in } \\
\text { ADLs }\end{array}$ \\
\hline $\begin{array}{l}\text { Fracture without threatened } \\
\text { myelum }\end{array}$ & S. Aureus & 21 & 2 & 777 & Success & DIAR + beads & No pain or disabilities in ADLs \\
\hline
\end{tabular}




\begin{tabular}{|c|c|c|c|c|c|c|c|}
\hline Diagnosis & pathogen & $\begin{array}{l}\text { Interval } \\
\text { (days) }\end{array}$ & $\begin{array}{l}\text { Debride- } \\
\text { ments }\end{array}$ & FU & Outcome & Treatment & Subjective outcome \\
\hline Spinal stenosis & S. Aureus & 21 & 3 & 1065 & Success & DIAR + beads & No pain or disabilities in ADLs \\
\hline $\begin{array}{l}\text { Fracture without threatened } \\
\text { myelum }\end{array}$ & S. Aureus & 21 & 2 & 5017 & Success & $\begin{array}{l}\text { Debribement, restabilization + } \\
\text { beads }\end{array}$ & Back pain \& disabilities in ADLs \\
\hline Fracture with threatened myelum & E. Coli & 22 & 1 & 1474 & Success & DIAR + beads & No pain or disabilities in ADLs \\
\hline Degenerative spondylolisthesis & S. Aureus & 23 & 2 & 1187 & Success & DIAR + beads & No pain or disabilities in ADLs \\
\hline Spinal stenosis & S. Aureus & 30 & 1 & 2770 & Success & DIAR + beads & Back pain, no disabilities in ADLs \\
\hline RIP with threatened myelum & S. Aureus & 31 & 1 & 42 & Failure & DIAR + beads & Dead \\
\hline RIP with threatened myelum & CNS & 33 & 2 & 583 & Success & $\begin{array}{l}\text { Debribement, restabilization }+ \\
\text { beads }\end{array}$ & No pain or disabilities in ADLs \\
\hline Degenerative spondylolisthesis & S. Aureus & 48 & 2 & 62 & Failure & $\begin{array}{l}\text { Debribement, restabilization + } \\
\text { beads }\end{array}$ & Dead \\
\hline RIP with threatened myelum & S. Aureus & 63 & 2 & 191 & Success & DIAR + beads & Back pain, no disabilities in ADLs \\
\hline Degenerative spondylolisthesis & G. elegans & 66 & 1 & 458 & Success & DIAR + beads & Leg pain, no disabilities in ADLs \\
\hline Degenerative spondylolisthesis & S. Aureus & 66 & 4 & 848 & Success & DIAR + fleeces & Back pain \& disabilities in ADLs \\
\hline $\begin{array}{l}\text { Fracture without threatened } \\
\text { myelum }\end{array}$ & P. acnes & 90 & 1 & 1112 & Success & DIAR, no local AB & No pain or disabilities in ADLs \\
\hline Degenerative spondylolisthesis & S. Aureus & 141 & 2 & 378 & Success & $\begin{array}{l}\text { Debribement, restabilization + } \\
\text { beads }\end{array}$ & No pain or disabilities in ADLs \\
\hline $\begin{array}{l}\text { Fracture without threatened } \\
\text { myelum }\end{array}$ & S. pneumoniae & 186 & 2 & 1080 & Success & DIAR + beads & Back pain, no disabilities in ADLs \\
\hline Failed previous spine surgery & negative & 265 & 1 & 1035 & Success & Removal implants + beads & Back pain \& disabilities in ADLs \\
\hline $\begin{array}{l}\text { Fracture without threatened } \\
\text { myelum }\end{array}$ & P. aeruginosa & 308 & 1 & 1336 & Success & Removal implants, no local $\mathrm{AB}$ & No pain or disabilities in ADLs \\
\hline Failed previous spine surgery & negative & 345 & 2 & 2920 & Success & Removal implants + beads & $\begin{array}{l}\text { Back \& leg pain \& disabilities in } \\
\text { ADLs }\end{array}$ \\
\hline $\begin{array}{l}\text { Fracture without threatened } \\
\text { myelum }\end{array}$ & S. intermedius & 402 & 2 & 1058 & Success & Removal implants, no local $\mathrm{AB}$ & Back pain \& disabilities in ADLs \\
\hline Failed previous spine surgery & P. acnes & 525 & 1 & 2105 & Success & Removal implants, no local $\mathrm{AB}$ & Back pain \& disabilities in ADLs \\
\hline $\begin{array}{l}\text { Fracture without threatened } \\
\text { myelum }\end{array}$ & P. acnes & 531 & 1 & 1157 & Success & Removal implants, no local $\mathrm{AB}$ & No pain or disabilities in ADLs \\
\hline $\begin{array}{l}\text { Degenerative disc } \\
\text { disease/discopathy }\end{array}$ & P. acnes & 691 & 1 & 1550 & Success & Removal implants, no local AB & Back pain \& disabilities in ADLs \\
\hline Fracture with threatened myelum & P. acnes & 934 & 1 & 811 & Success & Removal implants, no local $\mathrm{AB}$ & No pain or disabilities in ADLs \\
\hline Scoliosis, idiopathic & S. Aureus & 2723 & 1 & 756 & Success & Removal implants, no local $\mathrm{AB}$ & No pain or disabilities in ADLs \\
\hline Fracture with threatened myelum & CNS & 3292 & 1 & 1862 & Success & Removal implants, no local AB & No pain or disabilities in ADLs \\
\hline
\end{tabular}

Table 2. Operation related variables

\begin{tabular}{|c|c|c|c|c|c|c|}
\hline Operation-related variable & Overall & $\begin{array}{l}\text { Successful (42) } \\
\text { Infection treatment }\end{array}$ & $\begin{array}{l}\text { Failed (6) } \\
\text { Infection treatment }\end{array}$ & Odds-ratio & $95 \% \mathrm{Cl}$ & $p$-value \\
\hline \multicolumn{7}{|l|}{ Operation-indication } \\
\hline Fracture & $12(25.0 \%)$ & $10(23.8 \%)$ & $2(33.3 \%)$ & 0.625 & 0.099-3.935 & 0.616 \\
\hline Degenerative spine-disorders & $23(47.9 \%)$ & $21(50.0 \%)$ & $2(33.3 \%)$ & 2.000 & $0.329-12.123$ & 0.451 \\
\hline Spinal stenosis & $4(8.3 \%)$ & $4(9.5 \%)$ & 0 & 1.520 & $0.073-31.693$ & 0.787 \\
\hline Spinal metastasis & $5(10.4 \%)$ & $3(7.1 \%)$ & $2(33.3 \%)$ & 0.154 & $0.020-1.212$ & 0.076 \\
\hline Failed previous spine surgery & $2(4.2 \%)$ & $2(4.8 \%)$ & 0 & 0.803 & $0.035-18.677$ & 0.891 \\
\hline Other & $3(6.3 \%)$ & $3(7.1 \%)$ & 0 & 1.152 & $0.053-24.993$ & 0.928 \\
\hline Combined surgery (second incision) & $3(6.3 \%)$ & $3(7.1 \%)$ & 0 & 1.152 & $0.053-24.993$ & 0.928 \\
\hline \multicolumn{7}{|l|}{ Levels fused } \\
\hline Number & $2.6(1-9)$ & $2.6(1-9)$ & $3.2(1-6)$ & 1.042 & $0.683-1.590$ & 0.848 \\
\hline \multicolumn{7}{|l|}{ Anatomical levels } \\
\hline Thoracic & $7(14.6 \%)$ & $5(11.9 \%)$ & $2(33.3 \%)$ & 0.270 & $0.039-1.876$ & 0.186 \\
\hline Thoracolumbar & $8(16.7 \%)$ & $6(14.3 \%)$ & $2(33.3 \%)$ & 0.333 & $0.050-2.239$ & 0.258 \\
\hline Lumbar & $19(39.6 \%)$ & $18(42.9 \%)$ & $1(1.7 \%)$ & 3.750 & $0.402-34.957$ & 0.246 \\
\hline Lumbosacral & $13(27.1 \%)$ & $12(28.6 \%)$ & $1(1.7 \%)$ & 2.000 & $0.211-18.957$ & 0.546 \\
\hline Thoracic, lumbar and sacral & $1(2.1 \%)$ & $1(2.4 \%)$ & 0 & 0.470 & $0.017-12.813$ & 0.654 \\
\hline Bone graft & $41(85.4 \%)$ & $37(88.1 \%)$ & $4(66.7 \%)$ & 3.700 & $0.533-25.679$ & 0.186 \\
\hline Other than Autograft & $10(20.8 \%)$ & $7(16.7 \%)$ & $3(50.0 \%)$ & 0.200 & $0.033-1.203$ & 0.079 \\
\hline Cage used & $33(68.8 \%)$ & $31(73.8 \%)$ & $2(33.3 \%)$ & 5.636 & $0.903-35.189$ & 0.064 \\
\hline Dural tear & $7(14.6 \%)$ & $6(14.3 \%)$ & $1(16.7 \%)$ & 0.833 & $0.082-8.433$ & 0.877 \\
\hline \multicolumn{7}{|l|}{ Micro-organism } \\
\hline Staphylococcus Aureus & $24(50.0 \%)$ & $19(45.2 \%)$ & $5(83.3 \%)$ & 0,165 & $0,018-1,539$ & 0,114 \\
\hline Proprionibacterium acnes (spp.) & $1(2.1 \%)$ & $1(2.4 \%)$ & 0 & 0.470 & $0.017-12.813$ & 0.654 \\
\hline Coagulase negative staphylococcus & $3(6.3 \%)$ & $3(7.1 \%)$ & 0 & 1.152 & $0.053-24.993$ & 0.928 \\
\hline Enterobacter species & $9(18.8 \%)$ & $9(21.4 \%)$ & 0 & 3.687 & $0.190-71.525$ & 0.389 \\
\hline Streptococci species & $5(10.4 \%)$ & $5(11.9 \%)$ & 0 & 1.907 & $0.094-38.778$ & 0.675 \\
\hline Polymicrobial & $6(12.5 \%)$ & $5(11.9 \%)$ & $1(16.7 \%)$ & 0.676 & $0.065-7.024$ & 0.743 \\
\hline \multicolumn{7}{|l|}{ Soft tissue condition } \\
\hline Intact & $2(4.2 \%)$ & $1(2.4 \%)$ & $1(16.7 \%)$ & 0.122 & $0.007-2.268$ & 0.158 \\
\hline Open (wet) & $43(89.6 \%)$ & $38(90.5 \%)$ & $5(83.3 \%)$ & 1.900 & $0.176-20.560$ & 0.597 \\
\hline Abscess/ fistula & $3(6.3 \%)$ & $3(7.1 \%)$ & 0 & 1.152 & $0.053-24.993$ & 0.928 \\
\hline
\end{tabular}


Table 3. Patient related variables

\begin{tabular}{|c|c|c|c|c|c|c|}
\hline Patient-related variables & Overall (58) & $\begin{array}{l}\text { Successful (52) } \\
\text { infection treatment }\end{array}$ & $\begin{array}{l}\text { Failed (6) } \\
\text { infection treatment }\end{array}$ & Odds-ratio & $95 \% \mathrm{Cl}$ & $p$-value \\
\hline Man & $22(45.8 \%)$ & $19(45.2 \%)$ & $3(50.0 \%)$ & 0.826 & $0.149-4.576$ & 0.827 \\
\hline Woman & $26(46.6 \%)$ & $23(46.2 \%)$ & $3(50.0 \%)$ & 1.211 & $0.219-6.705$ & 0.827 \\
\hline Age & $58.3(19-83)$ & $56.3(19-83)$ & $65.1(37-80)$ & & & $0.177^{*}$ \\
\hline BMI & $28.2(17.7-41.3)$ & $28.3(17.7-41.3)$ & $28.1(22.4-34.7)$ & & & $0.327^{*}$ \\
\hline Obesity (BMI > 30) & $19(39.6 \%)$ & $18(42.9 \%)$ & $1(16.7 \%)$ & 3.750 & $0.402-34.957$ & 0.246 \\
\hline Smoking & $23(47.1 \%)$ & $21(50.0 \%)$ & $2(33.3 \%)$ & 2.000 & $0.330-12.123$ & 0.451 \\
\hline \multicolumn{7}{|l|}{ Comorbidities } \\
\hline Diabetes & $6(12.5 \%)$ & $5(11.9 \%)$ & $1(16.7 \%)$ & 0.676 & $0.065-7.024$ & 0.743 \\
\hline Pulmonary disease & $14(29.2 \%)$ & $13(31.0 \%)$ & $1(16.7 \%)$ & 2.241 & $0.238-21.150$ & 0.481 \\
\hline Rheumatic disease & $8(16.7 \%)$ & $7(16.7 \%)$ & $1(16.7 \%)$ & 1.000 & $0.101-9.928$ & 1.000 \\
\hline Cardiac disease & $11(22.9 \%)$ & $9(21.4 \%)$ & $2(33.3 \%)$ & 0.546 & $0.086-3.471$ & 0.521 \\
\hline Malignancy (active) & $6(12.5 \%)$ & $4(9.5 \%)$ & $2(33.3 \%)$ & 0.211 & $0.029-1.533$ & 0.124 \\
\hline ASA I & $9(18.8 \%)$ & $9(21.4 \%)$ & 0 & 3.687 & $0.190-71.525$ & 0.389 \\
\hline ASA II & $21(43.8 \%)$ & $20(47.6 \%)$ & $1(16.7 \%)$ & 4.546 & $0.488-42.307$ & 0.183 \\
\hline ASA III & $17(35.4 \%)$ & $12(28.6 \%)$ & $5(83.3 \%)$ & 0.080 & $0.008-0.758$ & 0.028 \\
\hline \multicolumn{7}{|l|}{ Medication } \\
\hline Use Steroid & $8(16.7 \%)$ & $6(14.3 \%)$ & $2(33.3 \%)$ & 0.333 & $0.050-2.239$ & 0.258 \\
\hline Use of immunosuppressive & $5(10.4 \%)$ & $3(7.1 \%)$ & $2(33.3 \%)$ & 0.154 & $0.020-1.212$ & 0.076 \\
\hline Trauma patient & $7(14.6 \%)$ & $5(11.9 \%)$ & $2(33.3 \%)$ & 0.270 & $0.039-1.876$ & 0.186 \\
\hline Polytraumatic injury & $2(4.2 \%)$ & $2(4.8 \%)$ & 0 & 0.803 & $0.035-18.677$ & 0.891 \\
\hline UCI admission & $3(6.3 \%)$ & $2(4.8 \%)$ & $1(16.7 \%)$ & 0.250 & $0.019-3.280$ & 0.291 \\
\hline $\begin{array}{l}\text { Radiation therapy after initial spine } \\
\text { surgery }\end{array}$ & $5(10.4 \%)$ & $3(7.1 \%)$ & $2(33.3 \%)$ & 0.154 & $0.020-1.212$ & 0.076 \\
\hline \multicolumn{7}{|l|}{ Blood values preop. } \\
\hline CRP & $169.3(6-584)$ & $152.6(6-584)$ & $298.5(209-414)$ & & & $0,412^{*}$ \\
\hline ESR & $57.7(10-120)$ & $55.7(10-112)$ & $75.2(47-120)$ & & & $0,617^{*}$ \\
\hline Leucocytes & $16.1(1-87)$ & $16.5(1-87)$ & $12.8(6.9-16.4)$ & & & $0.904^{*}$ \\
\hline Temperature preop. & $37.8(36.4-40.0)$ & $37.8(36.4-40.0)$ & $38.1(36.4-39.5)$ & & & $0.912^{*}$ \\
\hline Primary & $35(72.9 \%)$ & $30(76.2 \%)$ & $5(83.3 \%)$ & 0.500 & $0.053-4.739$ & 0.546 \\
\hline Revision & $13(27.1 \%)$ & $12(23.8 \%)$ & $1(16.7 \%)$ & 2.000 & $0.211-18.957$ & 0.546 \\
\hline $\begin{array}{l}\text { Interval surgery to start infection } \\
\text { symptoms }\end{array}$ & $33(1-186)$ & $34(1-186)$ & $24(10-49)$ & & & $0.667^{*}$ \\
\hline Preop. use of $\mathrm{AB}$ & $28(58.3 \%)$ & $24(57.1 \%)$ & $4(66.7 \%)$ & 0.667 & $0.110-4.050$ & 0.660 \\
\hline Postop. duration AB iv & $38.0(6-95)$ & $39.4(8-95)$ & $29.3(6-59)$ & & & $0.275^{*}$ \\
\hline Postop. duration AB oral & $48.6(0-196)$ & $47.7(14-133)$ & $55.0(0-196)$ & & & $0.412^{*}$ \\
\hline Postop. duration AB total & $78.7(6-251)$ & $79.3(15-201)$ & $75.2(6-251)$ & & & $0.242^{*}$ \\
\hline MIC-genta & $27.5(0.50-64)$ & $30.6(0.5-64)$ & $1.5(0.5-2.0)$ & & & $0.509^{*}$ \\
\hline Total number of gentamicin-beads & $123.3(0-240)$ & $121.4(0-240)$ & $142.5(120-180)$ & & & $0.412^{*}$ \\
\hline
\end{tabular}

*= Mann Withney U test

\section{Discussion}

The present study analyzed treatment of SSI and non-union in patients who underwent instrumented fusion of the thoracolumbar spine, with the use of gentamicin impregnated carriers. 42 of the 48 (87.5\%) patients showed successful resolution of infection with stable spinal fusion at the end of treatment, without recurrence of infection after a minimum of 1.5 years follow-up.

Although direct comparison with results from other studies in literature is difficult due to the heterogeneity of patient populations, the success rate of treatment in the present study appears to be quite high., Chen et al. reported an implant salvage success rate of $80.4 \%$ (41 in 51 patients) with repeated debridements (mean 1.7), systemic antibiotics, with adjunctive antibiotic-impregnated PMMA beads in 20 patients after a 2-year follow-up in patients with SSI after posterior spinal instrumentation.
In 8 of the $41(19.5 \%)$ successfully treated cases, solid fusion was not achieved. Furthermore, only 2 out of 10 patients $(20 \%)$ who underwent debridement with implant removal showed stable fusion. Unfortunately, the success rate of a subgroup of 20 patients who were treated with antibiotic loaded PMMA beads was not reported separately [29].

Glassman et al. treated 22 patients with SSI after instrumented spinal fusion with multiple debridements (mean 4.7), retention of the instrumentation, and antibiotic (tobramycin and vancomycin) impregnated PMMA beads. No patient showed recurrence of wound infection. Fusion was apparently solid in 14 patients, probable in four patients and nonunion occurred in one patient [30].

Compared to previous studies in which antibiotic carriers have not been used, the present study shows a favourable success rate. Kowalski et al. reported a success rate of $71 \%$ in 28 early onset spinal implant infections with retention of instrumentation, 
and $84 \%$ in 32 late onset spinal implant infections with operative debridement and removal of instrumentation [31]. Collins et al. reported a cure rate of $40 \%$ in 15 acute infections following instrumented spinal fusion with long-term (systemic) antibiotics and debridement with retention of the instrumentation [6]. The lower eradication rates observed in these studies clearly illustrate the added value of local antibiotic carriers in infection treatment after instrumented spine surgery in our opinion.

Kim et al. treated 20 patients with SSI between 1 and 5 months after instrumented spinal surgery with implant removal and wide debridement to clear the infection, despite the risk of disc space collapse and loss of normal lordosis. The infection was eradicated in all 20 patients after a minimum follow up of 2 years, but instability and/or pseudarthrosis at the fused segments was observed in 14 patients, thus resulting in a poor clinical outcome [32].

Several other supplemental procedures have been reported in the treatment of SSI after instrumented spinal fusion aside from the use of antibiotic impregnated PMMA beads, such as continuous suction irrigation, vacuum-assisted wound closure, or local tissue flap coverage. These studies are difficult to compare, because of the different treatment procedures. However the success rate of the present study is in the higher range of the success rates reported for these alternative supplemental procedures. Rohmiller et al. treated 28 patients with post-operative spinal infection with one operative session consisting of incision, drainage and closed suction irrigation. $75 \%$ of infections were resolved without recurrence after an average follow-up of 22.3 months. [33]

Mehbod et al. achieved a clean closed wound after an average follow-up of 10 months (6-24 months) in all of 20 patients with SSI after spinal fusion, treated with an average of $1.8(1-8)$ debridements prior to a vacuum-assisted wound closure procedure, and an ultimate VAC removal procedure in which the wound was closed over drains[34]. Labler et al. needed to exchange or remove the instrumentation in 12 of 13 infections after instrumented spinal surgery treated with vacuum assisted closure of the wound (15-40 months follow-up). One patient developed a recurrence infection at follow-up [35]. Sierra-Hoffman et al. reported a cure rate of $89 \%$ for early onset instrumented spinal infection in 19 patients by debridement with retention of the instrumentation, drainage and packed open with antibiotic solution soaked gauze and loose retention sutures. All patients returned to the operating room for follow-up debridement and closure over drains after 2-3 days, followed by systemic antibiotic administration. They noted a cure rate of $100 \%$ with no relapses for at least 3 years after therapy was reported in 7 late onset infections with removal of the instrumentation and 1 or 2 debridements [4].

In this study, a mean number of 2.3 (1-4) operations were needed including the removal of the PMMA beads, mostly a minor operation. Picada et al. reported that one-third of 26 patients required four or more debridements before obtaining a clean wound for closure [36]. Mehbod et al. reported a mean number of 3.25 (3-10) visits to the operating room to obtain a closed wound with vacuum-assisted wound closure in 20 patients [34].

In the present study $16.7 \%$ of the patients complained of residual disabling back pain at the end of the follow up, and $27.1 \%$ patients in total experienced limitations in activities of daily living because of residual back and/or leg pain. Similar to most studies in literature, our patients showed a less satisfactory outcome after instrumented spinal fusion with SSI compared with control groups without infection. [29, 37, 38]

We found Staphylococcus aureus (S. aureus) to be the most frequent $(24 / 48)$ causative microorganism of SSI. This is comparable to literature [6, 29, 33, 39]. International literature reports suggest an increasing prevalence of MRSA $[8,32]$, but MRSA was not cultured in our patients. This may be the result of the strict MRSA policy in the Netherlands [40].

Those patients with a failure of infection treatment had a significantly higher ASA score preoperatively as compared to the patients with a successful treatment. This difference is similar to findings in the literature on the infection treatment of hip and knee prosthesis infections [22, 23]. No firm conclusion can be drawn due to of lack of statistical power.

The present study has several limitations. The study design is retrospective, and although the number of 48 patients was adequate as compared to other studies in literature, there were only $6 / 58$ failures of treatment. The heterogeneity of patient and operation-related characteristics (time to infection treatment, indication of primary surgery, number of fused levels) in this study makes it hard to interpret outcome. A comparison to literature is even more difficult because of differences in treatment, definitions for outcome, patient characteristics, differences in surgical indications, and prevalence of micro-organisms. Another limitation was that the functional outcome was assessed by retrospective analysis of the files at the outpatient clinic.

All currently available clinical evidence regarding the treatment of postoperative infections after instrumented spinal surgery is based on 
uncontrolled retrospective studies. It is hard to conduct randomized controlled trials, as it would the cooperation of many centres in this field would be required due to the low infection rates and heterogeneity of patient populations.

A valuable alternative for future research would be setting up national and international registries to compare data of diagnosis, operations, comorbidity, and treatment of the infection and outcome variables in large patient populations. Although of lower internal validity as compared to RCT's, evidence of high external validity could be obtained in this way as the included patients would genuinely reflect daily clinical practice.

\section{Conclusion and Clinical Relevance}

Debridement and retention of instrumentation in combination with systemic antibiotics and the addition of local antibiotics (gentamicin impregnated PMMA beads or fleeces) results in successful treatment for SSI and non-union after instrumented spinal fusion.

\section{Competing Interests}

The authors have declared that no competing interest exists.

\section{References}

1. Schimmel JJ, Horsting PP, de Kleuver M, et al. Risk factors for deep surgical site infections after spinal fusion. Eur Spine J. 2010; 19(10): 1711-9.

2. Fang A, Hu SS, Endres $\mathrm{N}$, et al. Risk factors for infection after spinal surgery. Spine (Phila Pa 1976). 2005; 30(12): 1460-5.

3. Weinstein MA, McCabe JP, Cammisa, FP Jr. Postoperative spinal wound infection: a review of 2,391 consecutive index procedures. J Spinal Disord. 2000; 13(5): 422-6.

4. Sierra-Hoffman M, Jinadatha C, Carpenter JL, et al. Postoperative instrumented spine infections: a retrospective review. South Med J. 2010; 103(1): 25-30

5. Fang XT, Wood KB. Management of postoperative instrumented spinal wound infection. Chin Med J (Engl). 2013; 126(20): 3817-21.

6. Collins I, Wilson-MacDonald J, Chami G, et al. The diagnosis and management of infection following instrumented spinal fusion. Eur Spine J. 2008; 17(3): 445-50.

7. Godil SS, Parker SL, O'Neill KR, et al. Comparative effectiveness and cost-benefit analysis of local application of vancomycin powder in posterior spinal fusion for spine trauma: clinical article. J Neurosurg Spine. 2013; 19(3): 331-5.

8. Hegde V, Meredith DS, Kepler CK, et al. Management of postoperative spinal infections. World J Orthop. 2012; 3(11): 182-9.

9. Hedequist D, Haugen A, Hresko T, et al. Failure of attempted implant retention in spinal deformity delayed surgical site infections. Spine (Phila Pa 1976). 2009; 34(1): 60-4.

10. Trampuz A, Zimmerli W. Diagnosis and treatment of infections associated with fracture-fixation devices. Injury. 2006; 37 Suppl 2: S59-66.

11. Buchholz HW, Gartmann HD. [Infection prevention and surgical management of deep insidious infection in total endoprosthesis]. Chirurg. 1972; 43(10): 446-53

12. Wahlig H, Buchholz HW. [Experimental and clinical studies on the release of gentamicin from bone cement]. Chirurg. 1972; 43(10): 441-5.

13. Wahlig $\mathrm{H}$, Hameister $\mathrm{W}$, Grieben A. [Release of gentamicin from polymethyl methacrylate. I. Experimental in-vitro tests]. Langenbecks Arch Chir. 1972; 331(3): 169-92.

14. Wahlig H, Schliep HJ, Bergmann R, et al. [Release of gentamicin from polymethylmethacrylate. II. Experimental in vivo tests]. Langenbecks Arch Chir. 1972; 331(3): 193-212.
15. Wahlig H, Metallinos A, Hameister W, et al. [Gentamicin concentrations in tissues and body fluids of various animals]. Int J Clin Pharmacol. 1974; 10(3): 212-9.

16. Elson RA, Jephcott AE, McGechi DB, et al. Antibiotic-loaded acrylic cement. J Bone Joint Surg Br.1977; 59(2): 200-5.

17. Rasyid HN, van der Mei HC, Frijlink HW, et al. Concepts for increasing gentamicin release from handmade bone cement beads. Acta Orthop. 2009; 80(5): 508-13.

18. Wernet E, Ekkernkamp A, Jellestad H, et al. [Antibiotic-containing collagen sponge in therapy of osteitis]. Unfallchirurg. 1992; 95(5): 259-64.

19. Sorensen TS, Sorensen AI, Merser S. Rapid release of gentamicin from collagen sponge. In vitro comparison with plastic beads. Acta Orthop Scand. 1990; 61(4): 353-6.

20. Walenkamp GH, Vree TB, van Rens TJ. Gentamicin-PMMA beads. Pharmacokinetic and nephrotoxicological study. Clin Orthop Relat Res. 1986; (205): 171-83.

21. Buchholz HW, Elson RA, Engelbrecht E, et al. Management of deep infection of total hip replacement. J Bone Joint Surg Br. 1981; 63B(3): $342-53$

22. Geurts, JA, Janssen DM, Kessels AG, et al. Good results in postoperative and hematogenous deep infections of 89 stable total hip and knee replacements with retention of prosthesis and local antibiotics. Acta Orthop. 2013; 84(6): 509-16.

23. Janssen DM, Geurts JA, Jütten LM, et al. 2-stage revision of 120 deep infected hip and knee prostheses using gentamicin-PMMA beads. Acta Orthop. 2016; 1-9.

24. Swieringa AJ, Goosen JH, Jansman FG, et al. In vivo pharmacokinetics of a gentamicin-loaded collagen sponge in acute periprosthetic infection: serum values in 19 patients. Acta Orthop. 2008; 79(5): 637-42.

25. Mangram AJ, Horan TC, Pearson ML, et al. Guideline for prevention of surgical site infection, 1999. Hospital Infection Control Practices Advisory Committee. Infect Control Hosp Epidemiol. 1999; 20(4): 250-78.

26. Geubbels EL, Mintjes-de Groot AJ, van den Berg JM, et al. An operating surveillance system of surgical-site infections in The Netherlands: results of the PREZIES national surveillance network. Preventie van Ziekenhuisinfecties door Surveillance. Infect Control Hosp Epidemiol. 2000; 21(5): 311-8.

27. Carreon LY, Djurasovic M, Glassman SD, et al. Diagnostic accuracy and reliability of fine-cut CT scans with reconstructions to determine the status of an instrumented posterolateral fusion with surgical exploration as reference standard. Spine (Phila Pa 1976). 2007; 32(8): 892-5.

28. Fogel GR, Toohey JS, Neidre A, et al. Fusion assessment of posterior lumbar interbody fusion using radiolucent cages: X-ray films and helical computed tomography scans compared with surgical exploration of fusion. Spine J. 2008; 8(4): 570-7.

29. Chen $\mathrm{SH}$, Lee $\mathrm{CH}$, Huang $\mathrm{KC}$, et al. Postoperative wound infection after posterior spinal instrumentation: analysis of long-term treatment outcomes. Eur Spine J. 2015; 24(3): 561-70.

30. Glassman SD, Dimar JR, Puno RM, et al. Salvage of instrumental lumbar fusions complicated by surgical wound infection. Spine (Phila Pa 1976). 1996; 21(18): 2163-9.

31. Kowalski TJ, Berbari EF, Huddleston PM, et al. The management and outcome of spinal implant infections: contemporary retrospective cohort study. Clin Infect Dis. 2007; 44(7): 913-20.

32. Kim JI, Suh KT, Kim SJ, et al. Implant removal for the management of infection after instrumented spinal fusion. J Spinal Disord Tech. 2010; 23(4): 258-65.

33. Rohmiller MT, Akbarnia BA, Raiszadeh K, et al. Closed suction irrigation for the treatment of postoperative wound infections following posterior spinal fusion and instrumentation. Spine (Phila Pa 1976). 2010; 35(6): 642-6.

34. Mehbod AA, Ogilvie JW, Pinto MR, et al. Postoperative deep wound infections in adults after spinal fusion: management with vacuum-assisted wound closure. J Spinal Disord Tech. 2005; 18(1): 14-7.

35. Labler L, Keel M, Trentz O, et al. Wound conditioning by vacuum assisted closure (V.A.C.) in postoperative infections after dorsal spine surgery. Eur Spine J. 2006; 15(9): 1388-96.

36. Picada R, Winter RB, Lonstein JE, et al. Postoperative deep wound infection in adults after posterior lumbosacral spine fusion with instrumentation: incidence and management. J Spinal Disord. 2000; 13(1): 42-5.

37. Petilon JM, Glassman SD, Dimar JR, et al. Clinical outcomes after lumbar fusion complicated by deep wound infection: a case-control study. Spine (Phila Pa 1976). 2012; 37(16): 1370-4.

38. Mok JM, Guillaume TJ, Talu U, et al. Clinical outcome of deep wound infection after instrumented posterior spinal fusion: a matched cohort analysis. Spine (Phila Pa 1976). 2009; 34(6): 578-83. 
39. Ho C, Skaggs DL, Weiss JM, et al. Management of infection after instrumented posterior spine fusion in pediatric scoliosis. Spine (Phila Pa 1976). 2007; 32(24): 2739-44.

40. van der Zee A, Hendriks WD, Roorda L, et al. Review of a major epidemic of methicillin-resistant Staphylococcus aureus: the costs of screening and consequences of outbreak management. Am J Infect Control. 2013; 41(3): 204-9. 